\title{
Soft loan program for credit union: a fruitful or a useless program?
}

\author{
Ria Sandra Alimbudiono \\ University of Surabaya, Surabaya, Indonesia
}

\begin{abstract}
This study aims to give an insight about the performance evaluation on the government soft loan program in empowering credit union. This is a strategic program to improve the regional economy. Nevertheless, there is a contradictive view whether it is a fruitful or merely a useless program. Thus, a performance evaluation should be done. A naturalistic method was applied to get a deep understanding about the view of the leaders and members of the credit union regarding the implementation of the soft loan program and to know the performance of the credit union. Data collection methods were interviews, observations and documentation. Findings highlighted the successes, challenges and constraints that would ultimately be reflected in their performance. This study tried to capture the performance after six years from the beginning of soft loan program. Limitation and recommendations for future research were discussed.
\end{abstract}

Keywords: performance evaluation, soft loan program, credit union

\section{INTRODUCTION}

As a developing country, Indonesia needs to improve the economic welfare of the citizens. One of the efforts performed by the government through the Ministry of Cooperatives and Small and Medium Enterprises is launching the soft loan program for the credit union. Previous researches (García \& Mohnen 2010, Czarnitzki \& Lopes-Bento 2014, Liu \& Rammer 2016) stated that the government needed to offer soft loans or subsidy to institutions within their administration and assess the effectiveness of the funding.

Soft loan program is often related to controversy (Huergo \& Moreno 2017). Some parties consider soft loan program as a waste (Huergo \& Moreno 2017, Zúñiga-Vicente et al. 2014). On the other hand, other parties consider this program as a trigger for economic growth (Boesso et al. 2013, Poole \& Donovan 2014, Yang \& Hung 2014). Based on this phenomena gap, the objective of this study is to analyze the performance of credit union on the distribution of soft loan activity and the benefits felt by the leaders or members and all the problems, challenges, and empowerment of the society. The performance evaluation is using relative performance evaluation method (Elten 2017). This study gives benefits to the
Ministry of Cooperatives and Small and Medium Enterprises in obtaining feedback on the program and as a comparison and best practice for leaders of the other credit unions.

This study is divided into several sections. The first section describes the significance of soft loan in supporting the improvement of local economy and the objective of the study. Section 2 starts with a literature review regarding soft loan programs and the concept of performance evaluation. Section 3 presents the research methodology, followed by section 4 , which presents findings and all discussions. The conclusions and recommendations are set out in Section 5. Finally, the major limitations and future research of the work are explained in this section.

\section{LITERATURE REVIEW}

Soft loan program is one of the methods held by government in eradicating poverty (Pranarka \& Prijono 1996). A program is called as soft loan if the loan provides lower interest rate than the market rate (Huergo \& Moreno 2017). Soft loan program is given to institutions which are expected to trigger economic growth simultaneously. Along with the ongoing program, the government needs to perform an 
evaluation process (Corrigan \& Rixon 2017, Huergo $\&$ Moreno 2017). One of the applicable methods in performance evaluation is the relative performance evaluation (Elten 2017).

Relative performance evaluation is a means of determining the performance standard by using peer group benchmarking (Elten 2017, Liu \& Leitch 2013). Relative performance evaluation can be used as an instrument to assess the success of the program by comparing the achievement of the program among similar organization (Castro 2017). Performance evaluation begins by setting the purpose of the performance evaluation, formulating the key performance indicator, collecting the data, and finally measuring and assessing the financial or nonfinancial aspects. Financial performance evaluation can be performed through the financial report. While of the non-financial performance evaluation can be performed systematically according to the needs of the management and stakeholders. This performance evaluation tries to show the output and outcome related to the mission accomplishment. The effective application of relative performance evaluation does not require a lot of key performance indicators, but it requires several core key performance indicators in accordance with the purpose of the performance evaluation (Corrigan \& Rixon 2017, Michaud 2014).

\section{METHODS}

This study used a naturalistic approach (Tomkins \& Groves 1983) to get a deep understanding about the view and performance of the leaders and members of the women's credit union regarding the implementation and performance of the soft loan program. The unit analysis was credit union in one of the cities in East Java appointed as the pilot project. There were nine women's credit unions that were appointed as participants.

Data collection methods were interviews, observations and documentation. Semi-structured interview conducted to the leaders of the credit union and five members of each credit union. Non-participative observation was conducted by observing the credit distribution process, member gathering process and data recording process. Document analysis was performed on the Articles of Association, financial report, and various activity reports. The period of data collection was from February to July 2017. Validity and reliability data analysis were performed by triangulation test method (Silverman 2000).

\section{RESULTS AND DISCUSSION}

Soft loans were given to nine credit unions. The distribution of soft loan began by submitting credit union proposal to Ministry of Cooperatives and Small and Medium Enterprises in the municipality that went through to the Ministry of Cooperatives and Small and Medium Enterprises. Once passing the administrative selection, all soft loan recipient candidates were given intensive training and coaching on the importance of soft loan, acquaintance period of soft loan, rules and technicalities related to the distribution of soft loan to the members, data recording and reporting method on the performance of credit union. The intensive training and coaching would improve the competence, credibility and integrity for the leaders in managing fund. After all the preparation processes were passed, the leaders of the credit union would receive the soft loan that will due in five years. After disbursing the soft loan, the Ministry of Cooperatives and Small and Medium Enterprises would coach and evaluate the performance of credit unions every period in order to guarantee the success of the eradication of poverty through the soft loan program.

The first performance evaluation is conducted on the conformity of the rules that should be followed by the leaders of the credit union. There were five credit unions that did not obey the rules of service charge charged on the members which was $1 \%$. The leaders of the credit union charged service charge higher than the rules because they just follow the market rates, which was dominated by loan sharks. The leaders were hoping to receive a big surplus that can be used to grow the capital. However, they did not understand the essence of the soft loan given by the government, which was to help the marginal society to do productive business without the burden of high service charge.

The second performance evaluation is related to the benefit of the soft loan. The government provided soft loan program to the credit union expecting that the credit union can help its members in doing business. Of all the credit union receiving the soft loan, there were two that gave loan to the members for consumptive purpose, while nine other credit unions used it for productive purpose. This condition supports the opinion that the soft loan has been used to improve the income of the members. The leaders of the credit unions really care about the benefit of the soft loan because the leaders believe that the loan will be paid off if it is used for productive purposes. Thus, they will be responsible for the settlement of the loan. This situation shows that the soft loan has been beneficial to the marginal societies who need capital support for their business. Meanwhile, the 
leaders who give the soft loan for consumptive purpose believes that whatever purpose the members have is not their business as long as they are willing to settle the loan on time. It shows the lack of understanding of the leaders concerning the purpose of the program.

The success of the leaders in empowerment members who are mostly marginal society is the third performance evaluation. This success is marked by the number of liquid credit run by the credit union. There were three credit unions recorded for not having non-performing loan, and there were six credit unions that having non-performing loan around $20 \%-35 \%$. Other than that, there was one credit union that had $60 \%$ non-performing loan and one credit union that went bankrupt because of running out of capital due to non-performing loan. Nonperforming loan shows that the leaders of credit union are not excellent in managing the internal and external activities. The leaders of the credit union that did not have non-performing loan stated that the leaders have to help, motivate and support the members in managing fund or in marketing of the member's business. Proofs of the success in funding members business are as follows: A member of a credit union has improved her standard of living. Before getting the fund, she was selling toys by the street, but after getting support from credit unions, she can have a small shop in just five years. A member that sold food by walking around the alley can now own a food stall. While the credit union that stopped the business and was unable to settle the soft loan stated that the leaders did not have the time to manage the debtors. Besides, they also stated that they did not understand how to help the members.

Seen from the background of the leaders, one of the aspects that affect the success of the leaders is the education level. The credit union that bankrupt had a leader who is elementary school graduate. The low level of education has caused them lack of ability in understanding the importance of rules, the lack of patience in coaching, leading, and motivating the members so that the members could pay the installment and the service charge of the loan. The leaders were not capable of running the credit union business, since they did not do proper selections of the member. The leaders felt having enough training from government, but the leaders did not understand the material of the training well.

Credit unions which are able to maintain sustainability until six years after receiving the soft loan have leaders with high school or bachelor educational background. The leaders felt significant benefits of the training from the government. However, the leaders often had difficulties in implementing the training material in practice. The leaders had to un- derstand, implement, and improvise according to the condition in practice. Most of them were afraid and ashamed if the soft loan was not managed well, they would not be able to return the soft loan at the end of the loan period.

From the findings and discussions, it can be seen that the soft loan given by the credit union is very useful in empowering the rural societies' competence as the leaders or the members of the credit union. They receive training, understand rules, and try to achieve the objectives, and most importantly think and act productively. It is very important for them and the government in trying to improve the societies' welfare

\section{CONCLUSION}

The In general, the performance of the credit union has shown a positive result. The leaders of the credit union obey the rules and technical guidance given by the Ministry of Cooperatives and Small and Medium Enterprises, especially in terms of the service charge and the loan criteria for the members. The coaching given has provided great empowerment effects on the leaders, so that they understand how to manage, motivate and encourage the members and themselves to own a productive business. The presence of fear and shame, supported by the improved competence by the Office, has caused the leaders to be diligent, patient, and motivated in running the soft loan program well. Eventually, they give positive impact towards the increasing welfare of the members of credit union.

Theoretically, the management performance is affected and can be viewed from different factors. In this study, we limit the performance evaluation only on the obedience of rules and the number of nonperforming loan. Therefore, the future research may discuss different aspects of performance evaluation by using different research methodology.

\section{REFERENCES}

Boesso, G., Alessandro, H., \& Fabio, M. 2013. Governance and value creation in grant-giving foundations. Emerald Group Publishing Limited.

Castro, V.B. 2017. Unpacking the notion of subjectivity: performance evaluation and supervisor discretion. The British Accounting Review 49(6): 532-544.

Corrigan, L.T. \& Rixon, D. 2017. A dramaturgical accounting of cooperative performance indicators. Qualitative Research in Accounting \& Management 14(2): 60-80.

Czarnitzki, D. \& Lopes-Bento, C. 2014. Innovation subsidies: does the funding source matter for innovation intensity and performance? Empirical evidence from Germany. Industry and Innovation 21(5): 380-409. 
Elten, H.J. 2017. Relative performance evaluation among business unit level. Accounting Research Journal 30(2): 185204.

García, A. \& Mohnen, P. 2010. Impact of government support on R \& D and innovation UNU-MERIT. Working Paper Series 2010-034. United Nations University Maastricht

Huergo, E. \& Moreno, L. 2017. Subsidies or loans? evaluating the impact of R \& D support programmes. Research Policy 46: $1198-1214$.

Liu, L. \& Leitch, R. 2013. Performance effects of setting targets and pay-performance relations. Management Accounting Research 24(2): 64-79.

Michaud, V. 2014. Mediating the paradoxes of organizational governance through numbers. Organization Studies 35(1): 75-101.

Poole, N. \& Donovan, J. 2014. Building cooperative capacity: the specialty coffee sector in Nicaragua. Journal of agribusiness in developing and emerging economies 4(2): 133156.

Pranarka, A. \& Prijono, O.S. 1996. Pemberdayaan, konsep, kebijakan dan implementasi. Jakarta: CSIS.

Silverman, D. 2000. Doing qualitative research: a practical handbook. New York: Sage Publication.

Yang, X. \& Hung, K. 2014. Poverty alleviation via tourism cooperatives in China: the story of Yuhu. International Journal of Contemporary Hospitality Management 26(6): 879906.

Zúñiga-Vicente, J., Alonso-Borrego, C., Forcadell, F., \& Galán, J. 2014. Assessing the effect of public subsidies on firm R \& D investment: a Survey. Journal of Economic Survey 28(1): 36-67. 